\title{
Meta-analysis of postruminal microbial nitrogen flows in dairy cattle. I. Derivation of equations
}

\author{
Yairanex Roman-Garcia, ${ }^{*}$ Robin R. White, $†$ and Jeffrey L. Firkins**1 \\ *Department of Animal Sciences, The Ohio State University, Columbus 43210 \\ †Department of Dairy Science, Virginia Tech, Blacksburg 24060
}

\begin{abstract}
The objective was to summarize the literature and derive equations that relate the chemical composition of diet and rumen characteristics to the intestinal supply of microbial nitrogen (MicN), efficiency of microbial protein synthesis (EMPS), and flow of nonammonia nonmicrobial N (NANMN). In this study, 619 treatment means from 183 trials were assembled for dairy cattle sampled from the duodenum or omasum. Backward elimination multiple regression was used to derive equations to estimate flow of nitrogenous components over a large range of dietary conditions. An intercept shift for sample location revealed that omasal sampling estimated greater MicN flow relative to duodenal sampling, but sample location did not interact with any other variables tested. The ruminal outflow of MicN was positively associated with dry matter intake (DMI) and with dietary starch percentage at a decreasing rate (quadratic response). Also, MicN was associated with DMI and rumen-degraded starch and neutral detergent fiber (NDF). When rumen measurements were included, ruminal $\mathrm{pH}$ and ammonia- $\mathrm{N}$ were negatively related to MicN flow along with a strong positive association with ruminal isovalerate molar proportion. When evaluating these variables with EMPS, isovalerate interacted with ammonia such that the slope for EMPS with increasing isovalerate increased as ammonia- $\mathrm{N}$ concentration decreased. A similar equation with isobutyrate confirms the importance of branched-chain volatile fatty acids to increase growth rate and therefore assimilation of ammonia-N into microbial protein. The ruminal outflow of NANMN could be predicted by dietary NDF and crude protein percentages, which also interacted. This result is probably associated with neutral detergent insoluble $\mathrm{N}$ contamination of NDF in certain rumen-undegradable protein sources. Because NANMN
\end{abstract}

Received November 18, 2015

Accepted June 4, 2016.

${ }^{1}$ Corresponding author: firkins.1@osu.edu is calculated by subtracting MicN, sample location was inversely related compared with the MicN equation, and omasal sampling underestimated NANMN relative to duodenal sampling. As in the MicN equation, sampling location did not interact with any other variables tested for NANMN. Equations derived from dietary nutrient composition are robust across dietary conditions and could be used for prediction in protein supply-requirement models. These empirical equations were supported by more mechanistic equations based on the ruminal carbohydrate degradation and ruminal variables related to dietary rumen degradable protein. Key words: meta-analysis, rumen microbial nitrogen, dairy cattle

\section{INTRODUCTION}

Microbial protein supply to the dairy cow is the major source of MP and is well balanced in AA (NRC, 2001). Moreover, the prediction of microbial N flowing from the rumen (MicN) is pivotal in MP systems because nonammonia nonmicrobial N (NANMN) is derived from MicN predictions, and therefore the ability to manipulate metabolizable AA depends on both predictions.

The dairy NRC (2001) previously predicted MicN based on TDN intake, which was documented to have a minimal but significant linear bias (St-Pierre, 2003). The NRC (2001) also derived a method to predict RUP, but this approach had bias compared with experimentally derived NANMN flows (Bateman et al., 2005). However, the NRC (2001) equation still predicted MicN from intake of TDN, which ignores potential shifts in the site of digestion of starch (Firkins et al., 2001) and NDF (Firkins, 1997). Because TDN is rarely measured and typically is predicted from feed fractions (NRC, 2001) or from in vitro procedures in other models (Van Amburgh et al., 2015), MicN was hypothesized to be empirically predicted with improved fit based directly from dietary variables such as starch or NDF percentages or else be related mechanistically to rumen-derived measurements based on meta-analytical approaches. 
Meta-analyses have predicted MicN (or NANMN) based on duodenal sampling (Oldick et al., 1999), omasal sampling (Broderick et al., 2010), or both (Ipharraguerre and Clark, 2014). Comparisons of omasal and duodenal sampling were made in individual studies (Ipharraguerre et al., 2007). Correspondingly, omasal flow-derived MicN were compared with NRC predictions (Broderick et al., 2010), the latter of which were derived exclusively from duodenal sampling. However, no comprehensive comparisons have been done among sampling sites for dairy cattle using meta-analytical approaches that include a variety of dietary and ruminal fermentation characteristics that are related to MicN or NANMN flows from the rumen.

Ruminal microbes predominantly use carbohydrate, especially starch, for energy and for carbon skeletons promoting growth (Bach et al., 2005). However, prior efforts to predict ruminal starch and fiber digestibility to support microbial growth have had limitations compared with in vivo expectations (Firkins et al., 2008). Thus, combining more dietary combinations for duodenal and omasal sampling compared with previous attempts should allow more robust prediction of MicN flow from the rumen based on ruminal digestibilities of starch and NDF, which are the major sources of rumendegraded carbohydrate to support microbial growth. Increasing fermentable carbohydrate can limit MicN based on depressed ruminal $\mathrm{pH}$, and the efficiency of microbial protein synthesis (EMPS) can be decreased by limiting availability of branched-chain VFA (BCVFA) or $\mathrm{NH}_{3}-\mathrm{N}$ (Hoover, 1986). We assumed that BCVFA and $\mathrm{NH}_{3}-\mathrm{N}$ concentration could be collinearly related to dietary factors that influence ruminal fluid volume (the denominator of both concentrations) and therefore chose to evaluate BCVFA molar percentage. Although valerate can arise from glucose fermentation, the BCVFA only arise from RDP (Firkins et al., 2006). Because our objectives were to use data derived from studies in our database rather than using library values for RDP (few studies in our database directly measured $\mathrm{RDP}$ of their feeds), $\mathrm{NH}_{3}-\mathrm{N}$ concentration and BCVFA molar proportion were considered as mechanistic representations for the role of dietary RDP on maintaining EMPS with adequate rumen-degraded carbohydrate.

The objective of this study was to quantitatively summarize the body of literature reporting postruminal flows of nitrogenous components in dairy cattle to derive a suite of equations relating feed chemical composition to intestinal supply of MicN and NANMN. We hypothesized that unbiased estimates of MicN and EMPS could be derived from dietary chemical composition information and would be supported mechanistically by other equations derived from inclusion of rumi- nal carbohydrate digestibility and rumen fermentation variables.

\section{MATERIALS AND METHODS}

\section{Data Collection}

Data from the original articles used in the NRC (2001) dairy cattle models were used in this study (unless screened; see later) complemented with data from articles published up to 2015 that measured MicN flow and were written in English. Data were collected from different published articles across different journals. Key words used to search for relevant articles were omasal, duodenal, flow, dairy, microbial, nitrogen, digestibility, protein, passage, and starch in different combinations. Every article recovered, including reviews and metaanalyses, was screened for references with relevant titles for subsequent searches. If the title referred to animals other than dairy cattle, the article was not considered. Dissertations were not included in the data set, and we included only studies that used duodenal sampling from cannulas proximal to the pancreatic duct or omasal sampling through a rumen cannula because of potential problems with other sampling methods (Harmon and Richards, 1997; Titgemeyer, 1997). Articles that used near infrared reflectance spectrophotometry, urinary purine derivative excretion, or only reticular sampling to estimate MicN flow were excluded because these must be calibrated against measured duodenal or omasal flows of MicN (Firkins et al., 2006). Studies were also excluded when absolute passage or flow was not reported, when outdated techniques were used, or when markers were deemed inconsistent with acceptable practice (Firkins et al., 1998) or provided clearly discriminant outliers (e.g., one study reported negative starch digestibility in the rumen). When treatments had microbial modifiers (e.g., yeast), means were only retained if they were not different $(P>0.10)$ than their control. When the data set was evaluated for the effect of digesta flow and microbial markers, our preliminary screenings revealed that data with ADL as a flow marker clustered differently from results with other markers, whereas excluding studies with this marker had trivial subsequent effects on results in mixed models including the random effect of study. Because the same marker system was used within studies and we could detect no interactions with marker system, the differences among markers most likely aggregated into the random effect of study. Thus, the lignin-based data were retained because they were used in the NRC (2001) prediction. The final data set contained data from 183 articles and 613 treatment means. All the articles used in the data 
Table 1. Regression to estimate ammonia-N flow to the duodenum or omasum from total $\mathrm{N}$ flow

\begin{tabular}{lclll}
\hline Effect & Estimate & SE & df & $P$-value \\
\hline Intercept & -21.8 & 3.8 & 203 & $<0.0001$ \\
Total N $^{1}$ & 0.0535 & 0.0050 & 203 & $<0.0001$ \\
SMPLoc $^{2}$ & 15.5 & 2.2 & 203 & $<0.0001$ \\
\hline
\end{tabular}

${ }^{1}$ Total $\mathrm{N}$ flow from the rumen, grams per day.

${ }^{2}$ Sample location as factor and expressed relative to omasal sampling.

set are referenced in Supplemental Table S1 (http:// dx.doi.org/10.3168/jds.2015-10661).

\section{Data Cleaning}

When EMPS was not reported but OM truly degraded (OMTD) in the rumen was reported, microbial efficiency was calculated as follows:

$$
\operatorname{EMPS}=\frac{\operatorname{MicN}(\mathrm{g} / \mathrm{d})}{\mathrm{OMTD} \times \mathrm{OMI} \times 100},
$$

where $\mathrm{OMI}=\mathrm{OM}$ intake. Twenty-two articles did not correct for $\mathrm{NH}_{3}-\mathrm{N}$ and only reported total $\mathrm{N}$, microbial $\mathrm{N}$, and residual $\mathrm{N}$ (sometimes reported as feed $\mathrm{N}$ ). A regression was derived from total $\mathrm{N}$ using all of the articles that reported $\mathrm{NH}_{3}-\mathrm{N}$ flows to the duodenum (Table 1). These regressions showed parallel lines with the same slope but different intercepts for the sample location (omasal vs. duodenal). The equations were used to estimate $\mathrm{NH}_{3}-\mathrm{N}$ flow from the rumen and calculate the NANMN flow when it was not reported in the original study. Studies that only reported flows of NANMN corrected for endogenous $\mathrm{N}$ were converted back to uncorrected flows.

The pooled standard error of the mean for response variables per study was included as a weighting factor for the data. In previous studies (Oldick et al., 1999; Firkins et al., 2001), we weighted using the square of standard error of the mean. With cow-period as the experimental unit, however, weighting for the inverse of predicted variance based on $1 / \mathrm{SEM}^{2}$ has the potential to give too much weight for source data derived from Latin squares. A remedy is to weight for $1 / \mathrm{SEM}$ (N. R. St-Pierre, The Ohio State University, personal communication), which we followed herein. All of the articles in the data set were checked to determine whether the statistical method used a fixed effect or a mixed model and whether standard error of the mean, standard error of the difference (SED), or root mean square error (RMSE) were reported. In the 8 articles that used a mixed model but reported SED, standard error of the mean was calculated as described in the equation below and treated as a fixed effects model:

$$
\mathrm{SEM}=\frac{\mathrm{SED}}{\sqrt{2}} .
$$

If the article reported RMSE, then the standard error of the mean was calculated as stated below, where $n$ is the number of replications per treatment:

$$
\mathrm{SEM}=\frac{\mathrm{RMSE}}{\sqrt{n}} .
$$

When articles did not report standard error of the mean for the variables directly and when possible, the standard error of the mean was calculated using error propagation (Taylor, 1997). In 2 studies, an average standard error of the mean from other studies from that same laboratory was used as an estimate of standard error of the mean. When standard error of the mean could not be estimated by any of the above approaches, the data were not used. To prevent overweighting of the studies with extremely low standard error of the mean (Elliott, 2008), the standard error of the mean for MicN was truncated (i.e., trimmed) at half of the mean standard error of the mean (Firkins et al., 2001). Unlike for MicN models ( $<7.5 \%$ of SEM were trimmed), for EMPS and NANMN models, $\geq 17.4 \%$ of the standard errors of the mean were trimmed at half the mean standard error of the mean, which was deemed excessive; for those models, standard errors of the mean $<(0.25$ $\times$ mean SEM) were trimmed to one-fourth of the mean standard error of the mean. This trimming process was done separately for mixed and fixed effects models because mixed models tend to have higher standard error of the mean (Littell et al., 1998). After trimming, the reciprocal of the standard error of the mean was calculated separately for mixed and fixed effects models. Those reciprocals were standardized to (i.e., divided by) the mean of their respective distributions to normalize weighting factors to 1 . Thus, dependent variables were weighted for the reciprocal standard error of the mean without bias for fixed effects versus mixed models.

\section{Model Derivation Procedure}

Both PROC MIXED in SAS (SAS Institute, 1999) and lmer (Kuznetsova et al., 2013) in $\mathrm{R}$ version 3.1.0. ( $\mathrm{R}$ Core Team, 2014) were used and compared in the model derivation procedure for the first MicN equation. Because of complete congruency in all procedures and results, thereafter only $\mathrm{R}$ was used. To derive equations, 
backward elimination multiple regression was used. An initial model included all continuous and class variables that were considered a priori to potentially affect the response variable. Explanatory variables are identified in Table 2. In the first scenarios tested, DMI and ruminal digestibilities of starch (apparent) and NDF were tested in various combinations ranging from percentage to absolute $(\mathrm{kg} / \mathrm{d})$ bases. Second, DMI and all of the variables listed under diet composition were used in initial models for diet-level equations. In subsequent models, DMI, diet composition, and all rumen variables listed in Table 2 were introduced in initial models. All respective interaction and squared terms were assessed in all initial models and were re-evaluated with linear terms in final models as a check against local solutions. Study was added to every model as a random intercept effect, and sample location (omasal or duodenal sampling) was always included in initial models. The variable with the highest nonsignificant $(P>0.05) P$-value was iteratively eliminated from the model. During the backward elimination, nonsignificant $(P>0.05)$ linear effects were retained in the model if the corresponding quadratic or interaction term was significant $(P \leq 0.05)$. A final model produced all significant variables (unless a linear term was included with a significant quadratic term), and all variance inflation factors (VIF) were acceptable.

The VIF measure the severity of multicollinearity in a regression and reflect the degree to which parameter estimate variance is inflated due to collinearity with other parameter estimates. The square root of the VIF indicates the inflation of the variance of the parameter estimate compared with an ideal scenario of no collinearity. Although no concrete cutoffs for VIF have been agreed upon in the literature, we followed the example of previous studies (Oldick et al., 1999) and always removed variables with VIF $>100$ (variance 10 times larger than a model with no collinearity). In all cases reported herein, VIF were $<10$ (variance 3.2 times larger than a model with no collinearity) except for squared terms, which typically had VIF $>10$ (but always $<100$ ) because they are correlated by calculation. In this case, the collinearity is less of a concern when interpreting the model because the parameter is collinear with itself

Table 2. Summary statistics of data set

\begin{tabular}{|c|c|c|c|c|c|c|}
\hline Variable & $\mathrm{N}^{1}$ & Mean & Median & $\mathrm{SD}$ & Minimum & Maximum \\
\hline \multicolumn{7}{|c|}{ Animal and response variable ${ }^{2}$} \\
\hline DMI, kg/d & 590 & 19.3 & 19.7 & 4.2 & 3.8 & 30.4 \\
\hline $\mathrm{BW}, \mathrm{kg}$ & 527 & 597 & 600 & 58 & 319 & 788 \\
\hline DMI, $\%$ of BW & 500 & 3.24 & 3.25 & 0.64 & 0.95 & 5.25 \\
\hline Milk, kg/d & 469 & 28.7 & 28.3 & 7.8 & 10.2 & 47.0 \\
\hline Milk fat, $\%$ & 405 & 3.55 & 3.51 & 0.48 & 2.11 & 5.05 \\
\hline Milk protein, \% & 405 & 3.14 & 3.13 & 0.24 & 2.59 & 3.90 \\
\hline $\mathrm{MicN}$ & 611 & 275 & 262 & 102 & 52 & 743 \\
\hline EMPS & 490 & 28.7 & 27.9 & 8.2 & 12.0 & 54.0 \\
\hline NANMN & 602 & 204 & 204 & 83 & 26 & 576 \\
\hline \multicolumn{7}{|c|}{ Diet composition, ${ }^{3} \%$ of DM } \\
\hline Starch & 267 & 28.4 & 28.7 & 8.4 & 1.1 & 47.9 \\
\hline $\mathrm{NDF}$ & 470 & 32.8 & 32.4 & 5.7 & 17.6 & 50.9 \\
\hline $\mathrm{CP}$ & 564 & 17.2 & 17.3 & 2.1 & 10.3 & 25.2 \\
\hline NDFbyp & 495 & 2.09 & 0 & 4.46 & 0 & 27.17 \\
\hline \multicolumn{7}{|l|}{ Rumen variable $^{4}$} \\
\hline $\mathrm{pH}$ & 482 & 6.16 & 6.14 & 0.25 & 5.50 & 6.92 \\
\hline $\mathrm{NH}_{3}-\mathrm{N}, \mathrm{mg} / \mathrm{dL}$ & 464 & 12.9 & 14.1 & 5.4 & 1.4 & 40.6 \\
\hline iVal & 356 & 1.39 & 1.40 & 0.50 & 0.34 & 2.90 \\
\hline iBut & 311 & 1.00 & 0.90 & 0.31 & 0.26 & 2.30 \\
\hline dStRump & 246 & 61.1 & 61.6 & 18.3 & 4.5 & 96.7 \\
\hline dStRum & 178 & 3.80 & 3.82 & 1.43 & 0.30 & 7.35 \\
\hline dNDFRum & 293 & 2.84 & 2.65 & 1.15 & 0.10 & 7.17 \\
\hline OMTD $^{1}$ & 461 & 56.5 & 56.8 & 10.3 & 29.1 & 83.4 \\
\hline
\end{tabular}

${ }^{1} \mathrm{~N}=$ number of treatment means.

${ }^{2} \mathrm{MicN}=$ microbial $\mathrm{N}$ flow from the rumen $(\mathrm{g} / \mathrm{d})$; EMPS = efficiency of microbial protein synthesis $(\mathrm{g}$ of microbial $\mathrm{N} / \mathrm{kg}$ of $\mathrm{OM}$ truly degraded in the rumen); NANMN = nonammonia nonmicrobial $\mathrm{N}$ flow from the rumen $(\mathrm{g} / \mathrm{d})$.

${ }^{3} \mathrm{NDFbyp}=\mathrm{NDF}$ from byproducts in the diet (\% of DM). In almost all studies, enzymatic assays for starch or total nonstructural carbohydrates included residual sugars in their diet composition.

${ }^{4} \mathrm{iVal}=$ rumen isovalerate $(\mathrm{mol} / 100 \mathrm{~mol}$ of total VFA $)$; iBut = rumen isobutyrate $(\mathrm{mol} / 100 \mathrm{~mol}$ of total VFA); dStRum = degraded starch in the rumen (\% of starch intake, apparent basis); dStRump = degraded starch in the rumen $(\mathrm{kg} / \mathrm{d}$; dStRump $\times$ DMI/100); dNDFRum = degraded NDF in the rumen $(\mathrm{kg} / \mathrm{d}) ; \mathrm{OMTD}=\mathrm{OM}$ truly degraded in the rumen (\% of OM intake). 
and the inflation of the variance should be somewhat consistent between the 2 like terms. As a result, the interpretation of the individual parameter estimates is unlikely to be compromised.

\section{Evaluating Model Performance}

As explained by Boerman et al. (2015), we chose not to identify the root estimated variance of the model including study as RMSE, and we did not report RMSE after removing the random effect of study. Instead, the root estimated variance was $\hat{\sigma}_{e}$ (i.e., the estimated $\sigma$ for error), and the root estimated variance due to study is presented as $\hat{\sigma}_{s}$ (i.e., the estimated $\sigma$ for study). Both are expressed as percentages of the overall mean of the dependent variables. To compare among models of the same response variable, corrected Akaike information criterion (AICc) and concordance correlation coefficient were used, as explained in the companion paper (White et al., 2016). The AICc improved with each backward elimination step until our criteria were met. All variables were assessed for simple correlation coefficients (Table 3) to evaluate collinearity and error structure in the original data, and these correlations were sometimes used to assess potential for local solutions for fitting algorithms. Residual plots used data adjusted for the random effect of study, and the linear regressions were weighted for standard error of the mean to check for patterns; if bias was determined, additional interaction terms or elimination of variables were repeatedly evaluated until linear bias was insignificant or (in a few cases) deemed minor (White et al., 2016). When models were comparable, the one with more observations was deemed more desirable. In all models reported herein, if the random effect of study had a $P \leq 0.05$ intercept, the covariance between the intercept and slopes of continuous variables was always $P>0.10$ (St-Pierre, 2001).

\section{RESULTS AND DISCUSSION}

\section{Data Description}

A summary of the descriptive statistics of the data can be found in Table 2. Every variable has a different number of observations according to what was reported in each study. The minima and maxima document that the variables cover large ranges within the data set. The microbial $\mathrm{N}$ flow studies include 509 (there were 8 additional treatment means for ruminal digestibility for which there were no corresponding $\mathrm{MicN}$ flows) and 102 observations that used duodenal and omasal sampling, respectively.
Distinguishing Equations. In some situations, 2 final models were similar in fit performance; equations were presented herein based on fit criteria (Table 4) or were presented as alternate equations (Supplemental Table S2; http://dx.doi.org/10.3168/jds.2015-10661) for reasons explained subsequently. Equations were distinguished based on these fit statistics: $\hat{\sigma}_{e}$, concordance correlation coefficient, AICc, and $\mathrm{N}$; that is, number of treatment means. More complex models that contained the necessary inputs typically had lower $\mathrm{N}$. Because it is sensitive to N, any source data were temporarily screened if not common to both models for comparisons of AICc. When competing models were close, the simpler model or the one with a larger $\mathrm{N}$ was considered more parsimonious and selected. There should be no mean bias when evaluating residuals from the same source data; however, in some residual plots, linear bias was detected, and models were reassessed to reduce that bias. Residual plots corresponding with equations [1], [3], [4], [5], and [6] in Table 4 are in Supplemental Figures S1 to S5, respectively; similar plots corresponding with equations in Supplemental Table S2 are in Supplemental Figures S6 to S10 (http:// dx.doi.org/10.3168/jds.2015-10661). Even in some final models, the linear bias $(P \leq 0.05)$ could not be removed, but it was deemed acceptable in a few cases because it never contributed more than $3 \%$ of the mean square error. That the slope (if significant) was always small but positive probably reflects some underlying effect that was not associated with dietary variables used in these various equations. Study objectives were not used as exclusion criteria or assessed during model fitting. Although this common behavior might have some potential to influence model structure or parameter estimation, the consistent lack of interaction between study and explanatory variables suggests minimal risk for error or bias. Because the sampling location never interacted with other variables and was presented as a simple intercept shift, residual plots have only one slope representing both sampling locations.

\section{Sampling Location}

Omasal sampling was first derived as a technique to avoid the technical challenges of duodenal sampling (Firkins et al., 1998). Over time, sampling and marker procedures have improved and been standardized (Ahvenjärvi et al., 2001). A recent model derivation screened out all but omasal sampling protocols because most studies now use a triple marker system (Van Amburgh et al., 2015). Few duodenal sampling protocols incorporated a triple marker system. However, support is equivocal for using a double or triple marker 
PREDICTING MICROBIAL NITROGEN FLOW

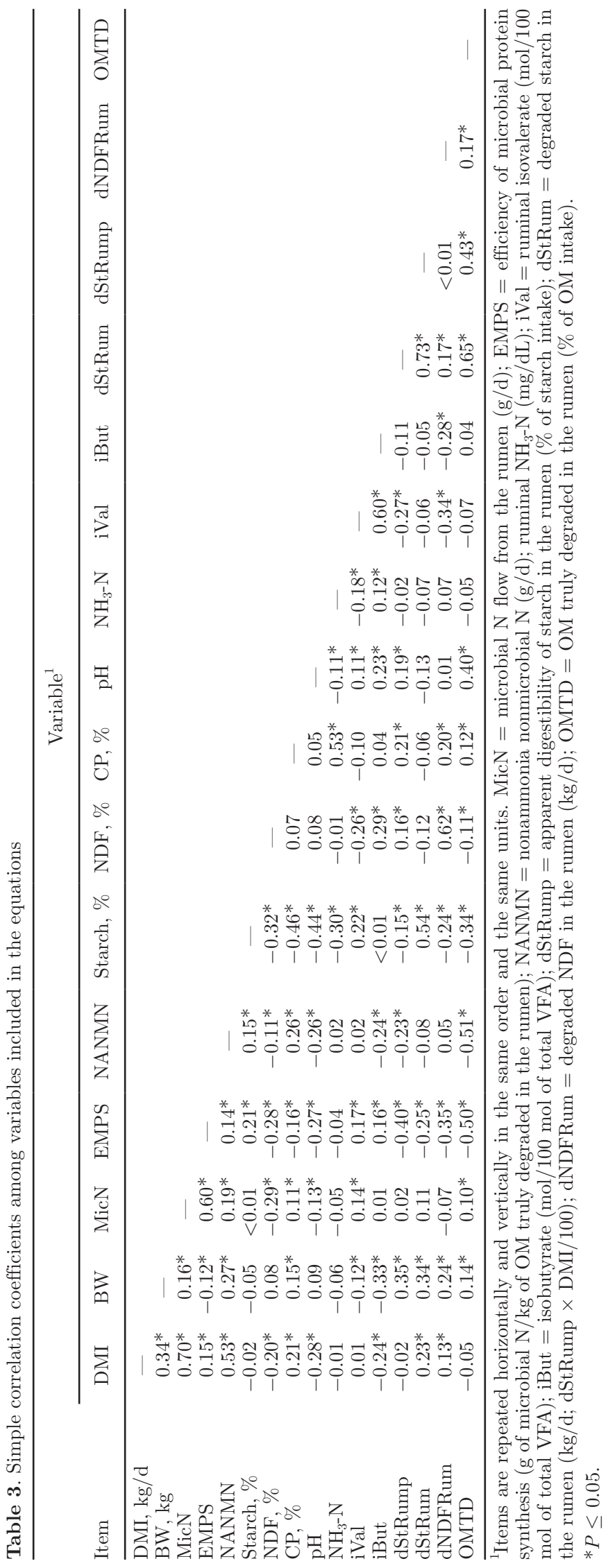


ROMAN-GARCIA ET AL.

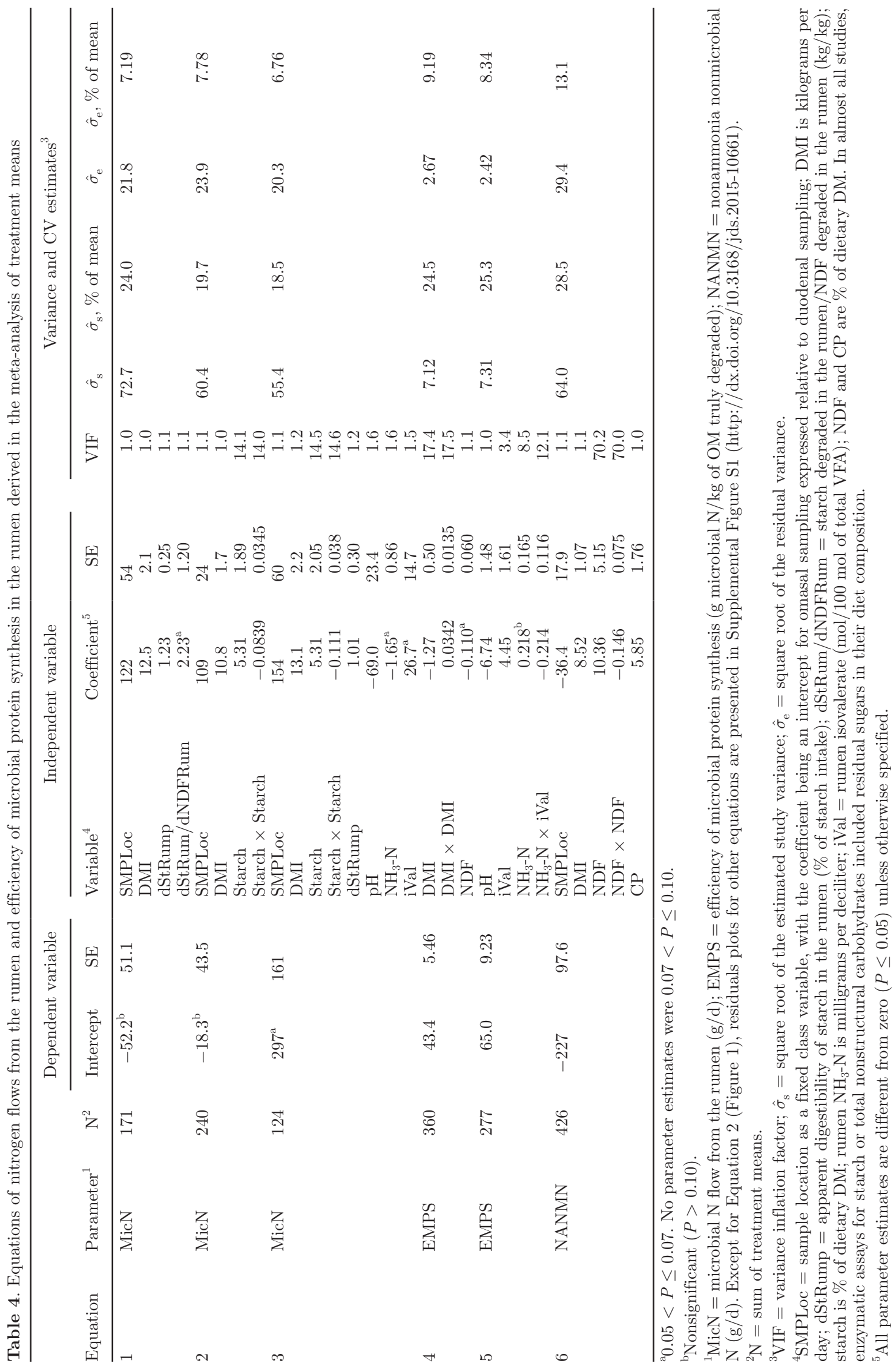


procedure to account for marker migration and other errors (although not for incomplete recovery) if duodenal sampling occurs around the diurnal flow schedule (Firkins et al., 1998). In contrast, the double and especially triple marker procedure helps mathematically correct for an unrepresentative sample, specifically for the nutrient concentration of this predicted true digesta sample. Such approaches were deemed necessary because omasal sampling likely under-represents larger particles. The triple marker approach does reconstitute the 3 phases of rumen contents available for passage (large particles, small particles, and fluid). However, there are important assumptions (e.g., markers have near $100 \%$ recovery and nutrients are represented among phases), and Reveneau et al. (2012) argued that sensitivity to error would increase as markers approached their bounds. Even if markers reconstitute their respective phases, MicN is not reconstituted directly because samples of microbes must be harvested according to their respective phases. In many studies, reticular or omasal samples were refrigerated before a pooled subsample was used to harvest bacteria sampled from fluid and particulate phases (aggregated across the small and large particles) or perhaps freezing before analyses dislodged some particulate bacteria (Huhtanen et al., 2014). Moreover, those authors documented the disparity in CP concentrations among particle size fractions of ruminal digesta, with the smallest size having a disproportionately high contribution to $\mathrm{N}$ outflow. Because bacteria have a much higher $\mathrm{N}$ concentration than feed, bacterial $\mathrm{N}$ might not distribute evenly with respective markers; thus, reconstitution of $\mathrm{N}$ might be challenged by this triple marked approach. Ipharraguerre et al. (2007) documented that flow of bacterial N was moderately greater for omasal than duodenal sampling using purines as a marker (about 15\%) but was much greater when ${ }^{15} \mathrm{~N}$ was used (about $45 \%$ ). When we evaluated the various microbial markers or sites for sampling bacterial cells, no consistent patterns emerged (the fixed class variables solid markers, liquid markers, and microbial markers had $P$-values of $0.83,0.21$, and 0.35 , respectively). Thus, we considered various deviations in sampling approaches to have no consistent bias, probably because of aggregation into the random effect of study. For all of these reasons, we retained data using single marker approaches with duodenal sampling and evaluated the sampling location (duodenum or omasum) as a class variable, further testing potential interactions with other variables in the model.

When we obtained the models for microbial $\mathrm{N}$, the sample location was significant for all models (Table 4, Equations 1, 2, and 3), documenting that omasal sampling consistently estimates greater MicN flow relative to duodenal sampling, which was the standard used in the NRC (2001) and has been noted previously (Broderick et al., 2010). Because sample location did not interact with any other variable, it was included in the model as a fixed class variable. By standardizing the equation to duodenal sampling, a prediction for omasal sampling would have the same slope but shift the intercept by the magnitude of the sampling location coefficient.

\section{Microbial Nitrogen Equations}

DMI. In all the equations for microbial N, DMI was uniformly positively associated, as expected for both duodenal (Bateman et al., 2005) and omasal (Broderick et al., 2010) MicN. Increasing DMI is logically associated with increasing intake of rumen-fermentable carbohydrate. Increasing DMI also can increase ruminal passage rate, which in turn decreases NDF digestibility but should increase EMPS by prioritizing growth versus nongrowth microbial functions (Firkins et al., 1998, 2007). Dijkstra et al. (1998b) summarized information describing why the increase in passage rate would increase bacterial growth rate to maintain the rumen microbial density relative to substrate supply.

Digestibility Equation. Because MicN is derived from rumen-degraded carbohydrate to provide carbon and ATP for protein synthesis and cell growth, the first equation focused on rumen-degraded starch and NDF. In those studies that measured ruminal digestibility of starch in our database, all but one used an assay that hydrolyzed starch to sugars without first extracting any sugars; consequently, we retained the terminology most often used in the source studies (i.e., starch), but we note herein that these are actually ruminal digestibilities of NSC (including sugars). The final model included DMI, the apparent digestibility of starch, and the ratio of starch degraded in the rumen to NDF degraded in the rumen (Equation 1; Table 4; Supplemental Figure S1; http://dx.doi.org/10.3168/ jds.2015-10661). The parameter estimate for the ratio is positive, which means increasing degraded starch or decreasing NDF has a positive relation with microbial N. Because the ratio factored out DMI, the low VIF documented low collinearity when DMI was a variable. To test a similar relationship with percentage ruminal digestibilities of starch and NDF, only starch digestibility met retention criteria and was positively related to MicN. The importance of starch as an energy source for ruminal microbes has been recognized for a long time (Nocek and Russell, 1988). Increasing ruminal starch digestibility can decrease ruminal NDF digestibility because of $\mathrm{pH}$-dependent and $\mathrm{pH}$-independent 
mechanisms (Firkins et al., 2007; Firkins, 2010). Many of the studies in our database had adequate forage NDF (averaging $24.2 \pm 7.1 \%$ ) and fed TMR to individual cows, which likely supported fibrolytic microbes. In some studies, nonforage NDF replaced forage NDF, so decreased NDF digestibility of forages might have been offset by the higher potential digestibility of nonforage NDF. Although degraded NDF provides energy to support microbial growth (and MicN flow), without further details of particle size or other mechanistic factors, our database was not sensitive enough for our MicN models to retain ruminal NDF digestibility as an explanatory variable; thus, any true relationships that could be distinguished from inverse correlation with starch digestibility were aggregated into the intercept. A prior meta-analysis of studies (Firkins et al., 2001) had categorical differences among grain sources, but all other terms besides DMI were eliminated from the microbial N model. Since then, many studies have measured ruminal starch digestibility, thus revealing its importance for predicting microbial $\mathrm{N}$ in the current analysis.

Diet-Level Equation. After verifying the role of rumen-degraded carbohydrate for MicN, we evaluated a diet-level model including DMI, starch, NDF, CP, and their interactions for potential direct usage without first predicting ruminal carbohydrate digestibility. Based on the low frequency for treatment means with added fat concomitantly with dietary starch $(\mathrm{n}=54)$ or ruminal starch digestibility $(\mathrm{n}=42)$ and the unlikely effect of fat on MicN flow (Schmidely et al., 2008), dietary fat concentration was not assessed. However, only SMPLoc, DMI, and starch remained in the model (Equation 2; Table 4). The squared term for starch indicated a limiting returns response, probably because increasing starch inclusion often decreases NDF percentage and ruminal NDF digestibility (Ferraretto et al., 2013). These results will be discussed subsequently with other rumen variables that could influence the response of starch response on MicN and EMPS. This equation had no significant pattern to its residuals (Figure 1). Moreover, Equation 2 was deemed more parsimonious than competing models with interaction terms or that pooled NDF among byproduct feeds (Equations 7 and 8 in Supplemental Table S2, respectively; http://dx.doi.org/10.3168/jds.201510661) that had similar $\hat{\sigma}_{e}$. There are differences in degradability characteristics of byproduct NDF (Firkins, 1997). Moreover, there are differences in ruminal starch digestibility that are ignored by including dietary starch as an explanatory variable, especially different processing methods (Firkins et al., 2001). However, inclusion of categorical values for differing grain process- ing methods offered no improvement (Equation 9; Supplemental Table S2; http://dx.doi.org/10.3168/ jds.2015-10661). None of the models in Supplemental Table S2 improved fit statistics compared with Equation 2 (Table 4), so it was deemed the most appropriate diet-level model.

Diet-Level Equation Including Rumen Variables. Introduction of rumen variables (Equation 3; Table 4; Supplemental Figure S2; http://dx.doi. org/10.3168/jds.2015-10661) maintained the importance of sampling location, DMI, and starch percentage; however, apparent ruminal starch digestibility, $\mathrm{pH}$, concentration of $\mathrm{NH}_{3}-\mathrm{N}$, and molar percentage of isovalerate were in the final model that included rumen variables. Taking into account only the effect of starch in the equation, the maximum (solving for zero from the partial derivative of the linear and quadratic terms) for dietary starch is $31.6 \%$ of inclusion in the diet for Equation 2, whereas the maximum is $23.9 \%$ for Equation 3. Apparent ruminal digestibility of starch was positively related to microbial N (Equation 3), explaining why dietary starch per se had a greater role in Equation 2. Dietary starch and apparent ruminal digestibility of starch were only moderately correlated (Table 3), and the VIF were modest in all cases. Thus, these 2 equations support the notion that progressively increasing dietary starch or increasing rumen-degraded starch increase risk that nitrogenous precursors limit the efficiency with which microbes convert degraded carbohydrate to cellular N. Ruminal $\mathrm{NH}_{3}-\mathrm{N}$ and molar

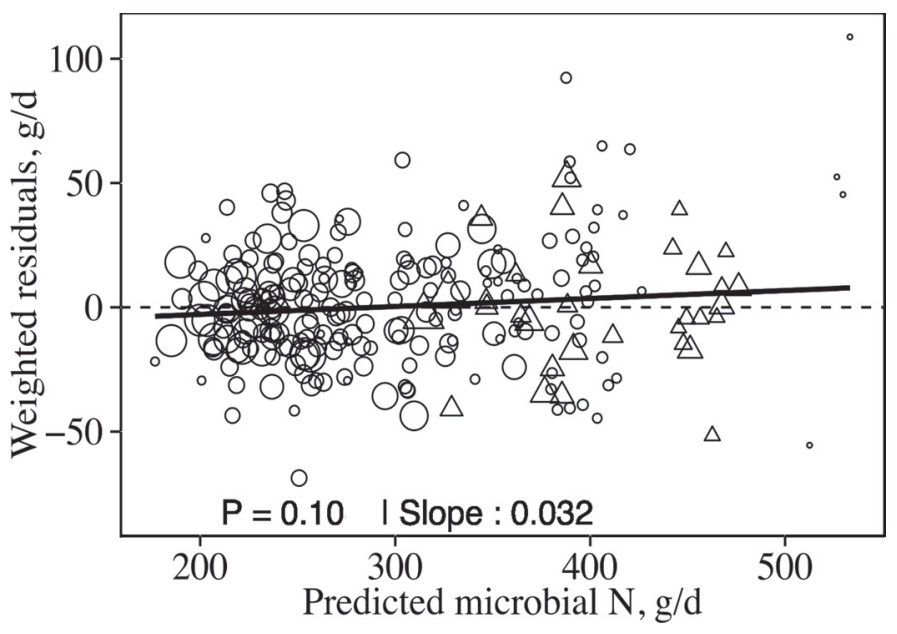

Figure 1. Weighted residuals (observed - predicted) versus predicted values for microbial $\mathrm{N}$ flow (Equation 2 from Table 4) for dairy cattle sampled from the omasum $(\Delta)$ or duodenum $(\bigcirc)$. The data points are sized based on the weight used in the model (size inversely proportional to SEM). The $P$-value and slope of the coefficient from linear regression (solid line) are shown above the x-axis. The slope bias contributed $2.78 \%$ of the mean square error. 
percentage of isovalerate were inversely and positively related to microbial N (Equation 3; Table 4). However, the rumen terms in Equation 3 will be discussed subsequently because their role for MicN is best explained through decreasing EMPS. Such a response also probably explains why introducing grain type did not improve the prediction of MicN (Equation 9; Supplemental Table S2; http://dx.doi.org/10.3168/jds.2015-10661).

\section{Microbial Efficiency Equations}

Statistical Considerations for EMPS. Although previously discussed efforts to relate MicN based on degraded ruminal carbohydrate (Equation 1) are based on expected biology (Firkins et al., 2007), the traditional measurement was based on MicN per unit of OM truly degraded. This efficiency ratio is based on flow and microbial markers used in calculations in both the numerator and denominator. Because both MicN (by strong association in Equations 1 to 3) and OMTD (collinear by calculation) are related to DMI, increasing DMI will increase both these variables much more than their EMPS quotient (e.g., partially factoring out the DMI effect, as demonstrated by Mic $\mathrm{N}$ ranging much more than does EMPS in Table 2). Assuming that increasing DMI increases EMPS through increased ruminal passage rate mechanistically and not just because it also dampens the OMTD denominator (Firkins et al., 2007), DMI should be positively associated with EMPS (Broderick et al., 2010). In contrast, the variance from both MicN and OMTD measurement should be additive in the EMPS calculation. Therefore, increasing EMPS through increased DMI should result in increased variation. Many of the large residuals with increasing EMPS in Supplemental Figures S3, S4, S9, and S10 (http:// dx.doi.org/10.3168/jds.2015-10661) have very small weights (i.e., high SEM). The size of the symbol and the linear bias (both its coefficient and $P$-value) reflect weighting in these plots. In a weighted regression, the weight of the data point is applied to the residuals or during the calculation of the likelihood function. The weighted residuals could have been plotted to show reduced visual evidence of heteroscedasticity (as we have verified). However, this plotting would require taking the product of the residuals and the weights, which would distort the units of the y-axis and inhibit assessment of the residual distribution in the same units as the response variable.

Diet-Level Equation. The EMPS was typically reported in studies and was predicted using dietary variables (Equation 4; Table 4; Supplemental Figure S3; http://dx.doi.org/10.3168/jds.2015-10661). When NDF was kept constant, the negative effect of DMI was minimized at $18.6 \mathrm{~kg} / \mathrm{d}$ of DMI (i.e., the partial derivative of the linear and quadratic terms for DMI) above which DMI was positively related to EMPS. Although a logical conclusion might be that increasing DMI did not increase ruminal passage rate in dairy cattle and therefore EMPS until DMI exceeded $18.6 \mathrm{~kg} / \mathrm{d}$, the effects were modest above that DMI. The negative coefficient for percentage NDF also was inconsistent with expectations. Fibrolytic bacteria have been modeled to have lower maintenance energy requirements than amylolytic bacteria (Russell et al., 1992; Russell et al., 2009). A competing equation with an interaction between DMI and NDF percentage (Equation 10, Supplemental Table S2; http://dx.doi.org/10.3168/jds.201510661) had similar $\hat{\sigma}_{e}$ but did not fit the data as well as Equation 4 based on fit statistics. This relationship illustrates the complexity in interpretation because DMI and dietary NDF percentage are related in opposing ways: increasing DMI increases ruminal passage rate and NDF digestibility, but dietary factors that improve NDF digestibility can alleviate ruminal fill and improve DMI (White et al., 2016). Starch and NDF are inversely correlated (Table 3), so variation in Equation 4 is partially related to that in Equation 2 and Equation 3 through collinearity even though only one of the variables remained in the final models.

Diet-Level Equation Including Rumen Variables. Using rumen variables known to influence EMPS (Equation 5; Table 4: Supplemental Figure S4; http://dx.doi.org/10.3168/jds.2015-10661) caused DMI and dietary NDF percentage to be eliminated from the model. Ruminal $\mathrm{pH}$ was inversely correlated with EMPS (Table 3), supporting the inverse relationship for microbial N noted before (Equation 3; Table 4). Table 2 documents that even $1 \mathrm{SD}$ below the mean ruminal $\mathrm{pH}$ is still above 5.9. Hoover (1986) documented that $\mathrm{pH}$ declining below 6.0 had a greater response to inhibit fiber degradation and disrupt ruminal ecology. Except in acidotic conditions, decreasing $\mathrm{pH}$ should have only a minor effect on efficiency of ATP usage (Russell et al., 2009). Thus, ruminal $\mathrm{pH}$ in our data set likely was typically not low enough to disrupt EMPS and, instead, was effectively capturing the indirect relationship between increased substrate availability (increased carbohydrate digestibility should decrease $\mathrm{pH}$ ) to support microbial growth (Bach et al., 2005).

The interaction between $\mathrm{NH}_{3}-\mathrm{N}$ and isovalerate on EMPS had a negative coefficient (Equation 5; Table 4), indicating that the slope for EMPS with increasing isovalerate increased as $\mathrm{NH}_{3}-\mathrm{N}$ concentration decreased. Because of the complexity in 3-dimensional responses, this interaction is illustrated with lines representing confidence intervals (Figure 2A) and the actual 3-di- 
A

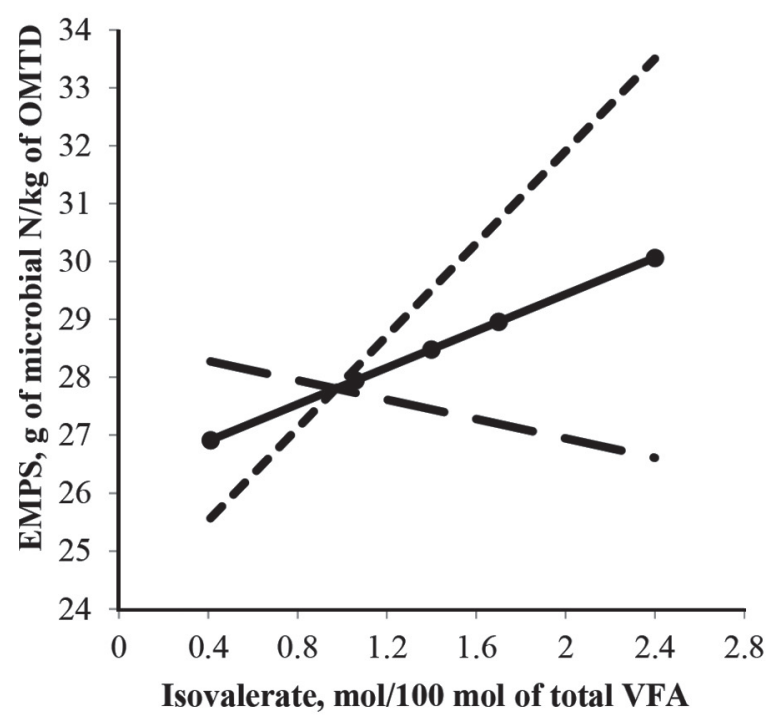

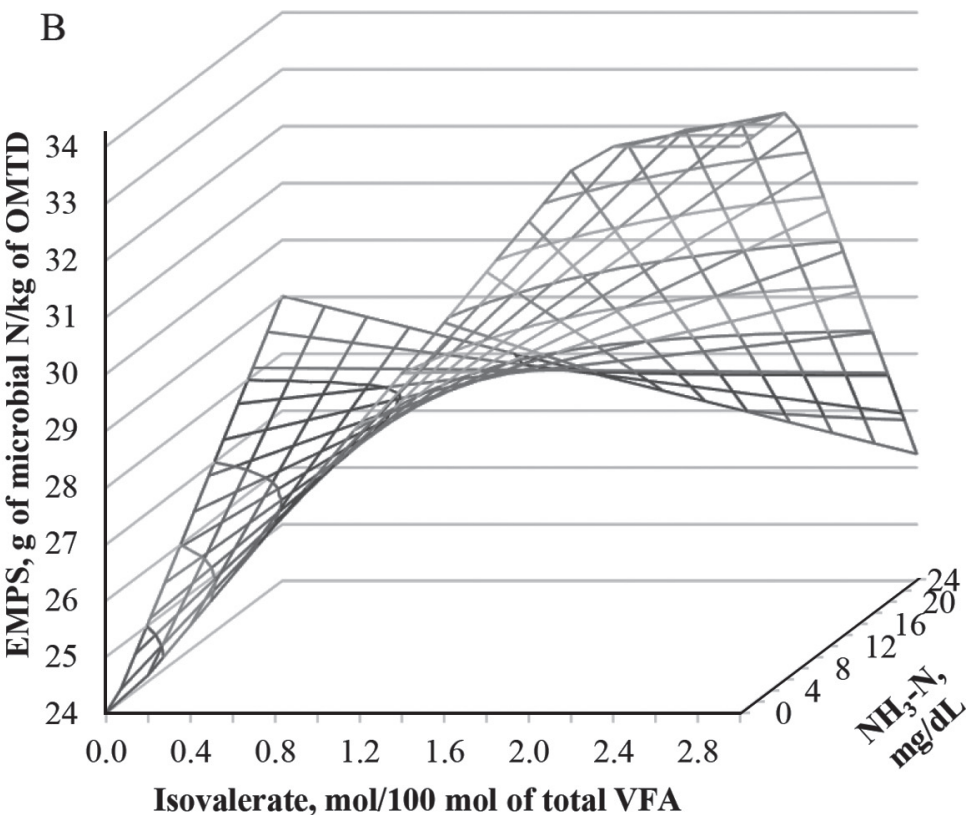

Figure 2. The interaction of rumen isovalerate (mol/100 mol of total VFA) and $\mathrm{NH}_{3}-\mathrm{N}(\mathrm{mg} / \mathrm{dL})$ on efficiency of microbial protein synthesis (EMPS; g of MicN/kg of OM truly degraded in the rumen), which is a component of Equation 5 in Table 4 . In panel A, the solid line (-) shows the response when $\mathrm{NH}_{3}-\mathrm{N}$ is fixed at its mean $(12.9 \mathrm{mg} / \mathrm{dL})$, and the points on the line represent ruminal isovalerate molar percentage at $-2 \mathrm{SD}$ from its mean, its first quartile, the mean $(1.40 \mathrm{~mol} / 100 \mathrm{~mol})$, the third quartile, and $+2 \mathrm{SD}$ from its mean, respectively, from left to right. The short-dashed line (- - ) represents the relationship between EMPS and isovalerate when $\mathrm{NH}_{3}-\mathrm{N}$ is $2 \mathrm{SD}$ below its mean (i.e., 2.1 mg/ $\mathrm{dL}$ ), and the long-dashed line (- - ) illustrates the response when $\mathrm{NH}_{3}-\mathrm{N}$ is $2 \mathrm{SD}$ above its mean (i.e., $23.7 \mathrm{mg} / \mathrm{dL}$ ). In panel B, the response surface is shown in 3 dimensions.

mensional plot (Figure 2B). The interaction between $\mathrm{NH}_{3}-\mathrm{N}$ and isovalerate molar percentage is expected based on studies dosing BCVFA and noting lower $\mathrm{NH}_{3-}$ N concentration (Andries et al., 1987). Those authors speculated that increasing bacterial growth decreased $\mathrm{NH}_{3}-\mathrm{N}$ concentration through assimilation to protein. Thus, lower $\mathrm{NH}_{3}-\mathrm{N}$ concentration and higher isovalerate (line with the highest slope in Figure 2A) would be positively associated with EMPS. In contrast, when $\mathrm{NH}_{3}-\mathrm{N}$ concentration was high, EMPS decreased with increasing isovalerate molar percentage (the line with the most negative slope in Figure 2A), suggesting that MicN was limited by some factor (such as energy), which allowed accumulation of both $\mathrm{NH}_{3}-\mathrm{N}$ and isovalerate. The intersection of lines in Figure 2A is approximately at the first quartile of isovalerate molar percentage and would suggest that very low isovalerate and very low ammonia limited EMPS and therefore MicN.

Compared with Equation 5 (Table 4), a competing model also had an interaction between $\mathrm{NH}_{3}-\mathrm{N}$ and isobutyrate (Equation 11, Supplemental Table S2; http://dx.doi.org/10.3168/jds.2015-10661), with neither model being significant if both isovalerate and isobutyrate were included at the same time. Based on similar fit statistics (including when AICc was used to compare models using data from studies that had both of these BCVFA), the isovalerate model was chosen because it had 45 more observations. Because of their strong correlation (Table 3), isovalerate and isobutyrate are accounting for similar sources of variation. This is not surprising because isobutyrate and isovalerate have similar functions to meet the BCVFA requirement, which is specific at least for cultured cellulolytics (Hoover, 1986). Allison et al. (1984) noted a rather consistent ratio depicting the need for 5-carbon BCVFA (2-methyl butyrate and isovalerate) and the 4-carbon BCVFA, isobutyrate. Moreover, leucine (produced from isovalerate) can be derived from valine (produced from isobutyrate) in Prevotella ruminicola (Allison et al., 1984) and in other ruminal bacteria, based on a pathway search of the Hungate 1000 draft genomes, as described by Hackmann and Firkins (2015). The concentration of the BCVFA depends on production from branched-chain AA, uptake of BCVFA into BCAA or longer chain branched fatty acids (Vlaeminck et al., 2006), or perhaps interactions between the branchedchain AA.

Both isovalerate and isobutyrate have important functions in ruminal bacterial ecology. Isovalerate's respective BCAA, leucine, is likely an important amino donor in methionine metabolism and also has a potential role in the CodY transcription regulator of enzymes 
needed for de novo synthesis of AA (Firkins et al., 2015). Unfortunately, some of the isovalerate response also might be partly an artifact because 2-methyl butyrate (another important BCVFA) elutes very closely with isovalerate (also called 3-methyl butyrate) and needs careful adjustment of GLC conditions (Dehority et al., 1967); almost all of the studies from our database did not report 2-methyl butyrate, probably because of coelution with isovalerate. The concentration of the BCVFA is important but challenging to model in part because their concentration depends on carbohydrate substrate (Dijkstra et al., 1998a). Several studies have suggested that passage of soluble protein or peptides is significant with dairy cattle fed at high DMI and with a fast ruminal passage rate (Broderick et al., 2010). Under these conditions, direct uptake of preformed AA or BCVFA derived from BCAA might also limit concentration of ammonia or BCVFA below what is needed to support maximal growth (Hoover, 1986), forcing synthesis of BCAA from glucose or acetate (Allison et al., 1984). Both isovalerate (Liu et al., 2014) and isobutyrate (Wang et al., 2015) increased cellulolytic bacteria and fungal zoospores, fibrolytic bacterial $16 \mathrm{~S}$ rRNA abundance, and fibrolytic activity in beef cattle fed higher forage diets. However, taken as a proxy for RDP in dairy diets with lower inclusion of better quality forage, both equations including the interactions between $\mathrm{NH}_{3}-\mathrm{N}$ and isovalerate (or isobutyrate) also appear to support a role for RDP to stimulate MicN when rumen-degraded carbohydrate is in excess or in a co-limiting role (White et al., 2016). Unfortunately, RDP was rarely derived directly in source data, and calculation of RDP from duodenal NANMN should be avoided in models with MicN (Galyean and Tedeschi, 2014). Experimental error that overestimates MicN will automatically underestimate NANMN and RUP (thereby overestimating RDP) within study (and vice versa for error underestimating MicN); thus, relationships between RDP and MicN both based on the same flow data are biased.

\section{Nonammonia, Nonmicrobial Nitrogen}

The NANMN flow was predicted using dietary variables (Equation 6; Table 4; Supplemental Figure S5; http://dx.doi.org/10.3168/jds.2015-10661) that are different from the variables used for microbial $\mathrm{N}$ because NANMN is primarily related to RUP of diet ingredients. As with microbial N, sample location was a significant class variable that also did not interact with DMI. Because NANMN is calculated by subtracting microbial $\mathrm{N}$, which is overestimated relative to duodenal sampling (or vice versa), omasal sampling underestimates NANMN relative to duodenal sampling. In this equa- tion, NDF percentage of the diet was associated with increasing NANMN at a decreasing rate, and CP was positively related. Because Weiss et al. (1992) predicted NDIN (multiplied by 6.25 to convert to CP) based on NDF and CP, the current relationship is probably a result of increasing NDIN, which was rarely measured in studies in our data set but is an index of heating to increase RUP (Merchen et al., 1997). Several of the studies included heated protein sources or contained grain byproducts that have significant NDIN contamination of NDF and have higher RUP than conventional protein sources such as soybean meal. Moreover, increasing forage maturity likely increases RUP (Balde et al., 1993; De Visser et al., 1998). Because increasing maturity also increases NDF, some of the relationship between NDF and NANMN might be a result of differing maturities of forages in our source data. Although feed-specific RUP would presumably improve prediction of NANMN (lowering residuals and removing the minor slope bias), the current approaches to estimate RUP suffer from issues related to assumptions of no passage from the soluble pool and from microbial $\mathrm{N}$ contamination of residual feed after incubation (Huhtanen et al., 2014) and have bias (Bateman et al., 2005; Pacheco et al., 2012).

\section{CONCLUSIONS}

Our study performed meta-analyses predicting microbial $\mathrm{N}$ based on diet-level variables without or with rumen variables. Omasal sampling was predicted to increase microbial $\mathrm{N}$ flow compared with duodenal sampling, but this fixed class variable did not interact with any other variable. In most equations, DMI was a major driver, which is consistent with conclusions from previous meta-analyses. Prediction based on the rumen variables mechanistically supports microbial $\mathrm{N}$ being empirically predicted based on DMI and dietary starch percentage. The effect of the individual and collective concentration of the BCVFA needs to be studied to better understand its effect on microbial growth. Based on diet-level variables, the flow of NANMN could be predicted based on dietary NDF and CP percentages, although feed-specific prediction might improve this prediction.

\section{ACKNOWLEDGMENTS}

This work was carried out and supported, partially, as an activity of the National Animal Nutrition Program (NANP) to provide enabling technologies, support, and shared resources to the research community. The NANP, a National Research Support Project (NRSP-9) of State Agricultural Experiment Stations, is 
funded from Hatch funds administered by the National Institute of Food and Agriculture, US Department of Agriculture, Washington, DC. Research was supported by state and federal funds appropriated to the Ohio Agricultural Research and Development Center, The Ohio State University, manuscript number 10/16AS.

\section{REFERENCES}

Ahvenjärvi, S., B. Skiba, and P. Huhtanen. 2001. Effect of heterogeneous digesta chemical composition on the accuracy of measurements of fiber flow in dairy cows. J. Anim. Sci. 79:1611-1620.

Allison, M. J., A. L. Baetz, and J. Wiegel. 1984. Alternative pathways for biosynthesis of leucine and other amino acids in Bacteroides ruminicola and Bacteroides fragilis. Appl. Environ. Microbiol. 48:1111-1117

Andries, J. I., F. X. Buysse, D. L. De Brabander, and B. G. Cottyn 1987. Isoacids in ruminant nutrition: Their role in ruminal and intermediary metabolism and possible influences on performancesA review. Anim. Feed Sci. Technol. 18:169-180.

Bach, A., S. Calsamiglia, and M. D. Stern. 2005. Nitrogen metabolism in the rumen. J. Dairy Sci. 88(E. Suppl.):E9-E21.

Balde, A. T., J. H. Vandersall, R. A. Erdman, J. B. Reeves Iii, and B. P. Glenn. 1993. Effect of stage of maturity of alfalfa and orchardgrass on in situ dry matter and crude protein degradability and amino acid composition. Anim. Feed Sci. Technol. 44:29-43.

Bateman, H. G., J. H. Clark, and M. R. Murphy. 2005. Development of a system to predict feed protein flow to the small intestine of cattle. J. Dairy Sci. 88:282-295.

Boerman, J. P., J. L. Firkins, N. R. St-Pierre, and A. L. Lock. 2015. Intestinal digestibility of long-chain fatty acids in lactating dairy cows: A meta-analysis and meta-regression. J. Dairy Sci. 98:88898903.

Broderick, G. A., P. Huhtanen, S. Ahvenjarvi, S. M. Reynal, and K. J. Shingfield. 2010. Quantifying ruminal nitrogen metabolism using the omasal sampling technique in cattle - A meta-analysis. J. Dairy Sci. 93:3216-3230.

De Visser, H., A. Klop, C. J. Van der Koelen, and A. M. Van Vuuren. 1998. Starch supplementation of grass harvested at two stages of maturity prior to ensiling: Intake, digestion, and degradability by dairy cows. J. Dairy Sci. 81:2221-2227.

Dehority, B. A., H. W. Scott, and P. Kowaluk. 1967. Volatile fatty acid requirements of cellulolytic rumen bacteria. J. Bacteriol. 94:537-543.

Dijkstra, J., J. France, and D. R. Davies. 1998a. Different mathematical approaches to estimating microbial protein supply in ruminants. J. Dairy Sci. 81:3370-3384.

Dijkstra, J., J. France, and S. Tamminga. 1998b. Quantification of the recycling of microbial nitrogen in the rumen using a mechanistic model of rumen fermentation processes. J. Agric. Sci. 130:81-94.

Elliott, M. R. 2008. Model averaging methods for weight trimming. J. Off. Stat. 24:517-540.

Ferraretto, L. F., P. M. Crump, and R. D. Shaver. 2013. Effect of cereal grain type and corn grain harvesting and processing methods on intake, digestion, and milk production by dairy cows through a meta-analysis. J. Dairy Sci. 96:533-550.

Firkins, J. L. 1997. Effects of feeding nonforage fiber sources on site of fiber digestion. J. Dairy Sci. 80:1426-1437.

Firkins, J. L. 2010. Reconsidering rumen microbial consortia to enhance feed efficiency and reduce environmental impact of ruminant livestock production systems. Rev. Bras. Zootec. 39:445-457.

Firkins, J. L., M. S. Allen, B. S. Oldick, and N. R. St-Pierre. 1998. Modeling ruminal digestibility of carbohydrates and microbial protein flow to the duodenum. J. Dairy Sci. 81:3350-3369.

Firkins, J. L., M. L. Eastridge, N. R. St-Pierre, and S. M. Noftsger. 2001. Effects of grain variability and processing on starch utilization by lactating dairy cattle. J. Anim. Sci. 79(E. Suppl.):E218E238.
Firkins, J. L., C. M. Fowler, E. Devillard, and B. J. Bequette. 2015 Kinetics of microbial methionine metabolism in continuous cultures administered different methionine sources. J. Dairy Sci. 98:1178-1194.

Firkins, J. L., A. N. Hristov, M. B. Hall, G. A. Varga, and N. R. StPierre. 2006. Integration of ruminal metabolism in dairy cattle. J. Dairy Sci. 89(E. Suppl.):E31-E51.

Firkins, J. L., S. K. R. Karnati, and Z. Yu. 2008. Linking rumen function to animal response by application of metagenomics techniques. Aust. J. Exp. Agric. 48:711-721.

Firkins, J. L., Z. Yu, M. Morrison, and M. Morrison. 2007. Ruminal nitrogen metabolism: Perspectives for integration of microbiology and nutrition for dairy. J. Dairy Sci. 90(E. Suppl.):E1-E16.

Galyean, M. L., and L. O. Tedeschi. 2014. Predicting microbial protein synthesis in beef cattle: Relationship to intakes of total digestible nutrients and crude protein. J. Anim. Sci. 92:5099-5111.

Hackmann, T. J., and J. L. Firkins. 2015. Electron transport phosphorylation in rumen butyrivibrios: Unprecedented ATP yield for glucose fermentation to butyrate. Front. Microbiol. 6:622.

Harmon, D. L., and C. J. Richards. 1997. Considerations for gastrointestinal cannulations in ruminants. J. Anim. Sci. 75:2248-2255.

Hoover, W. H. 1986. Chemical factors involved in ruminal fiber digestion. J. Dairy Sci. 69:2755-2766.

Huhtanen, P., A. Bayat, S. J. Krizsan, and A. Vanhatalo. 2014. Compartmental flux and in situ methods underestimate total feed nitrogen as judged by the omasal sampling method due to ignoring soluble feed nitrogen flow. Br. J. Nutr. 111:535-546.

Ipharraguerre, I. R., and J. H. Clark. 2014. A meta-analysis of ruminal outflow of nitrogen fractions in dairy cows. J. Adv. Dairy Res. $2: 122$.

Ipharraguerre, I. R., S. M. Reynal, M. Liñeiro, G. A. Broderick, and J. H. Clark. 2007. A comparison of sampling sites, digesta and microbial markers, and microbial references for assessing the postruminal supply of nutrients in dairy cows. J. Dairy Sci. 90:1904-1919.

Kuznetsova, A., P. Brockhoff, and R. Christensen. 2013. Lmertest: Test for random and fixed effects for linear mixed effects models (lmer objects of lme4 package). R package version: 2.0-0.

Littell, R. C., P. R. Henry, and C. B. Ammerman. 1998. Statistical analysis of repeated measures data using SAS procedures. J. Anim. Sci. 76:1216-1231.

Liu, Q., C. Wang, C. X. Pei, H. Y. Li, Y. X. Wang, S. L. Zhang, Y. L. Zhang, J. P. He, H. Wang, W. Z. Yang, Y. S. Bai, Z. G. Shi, and X. N. Liu. 2014. Effects of isovalerate supplementation on microbial status and rumen enzyme profile in steers fed on corn stover based diet. Livest. Sci. 161:60-68.

Merchen, N. R., J. C. Elizalde, and J. K. Drackley. 1997. Current perspective on assessing site of digestion in ruminants. J. Anim. Sci. 75:2223-2234

Nocek, J. E., and J. B. Russell. 1988. Protein and energy as an integrated system. Relationship of ruminal protein and carbohydrate availability to microbial synthesis and milk production. J. Dairy Sci. 71:2070-2107.

NRC. 2001. Nutrient Requirements of Dairy Cattle. National Academies Press, Washington, DC.

Oldick, B. S., J. L. Firkins, and N. R. St-Pierre. 1999. Estimation of microbial nitrogen flow to the duodenum of cattle based on dry matter intake and diet composition. J. Dairy Sci. 82:1497-1511.

Pacheco, D., R. A. Patton, C. Parys, and H. Lapierre. 2012. Ability of commercially available dairy ration programs to predict duodenal flows of protein and essential amino acids in dairy cows. J. Dairy Sci. 95:937-963.

R Core Team. 2014. R: A Language and Environment for Statistical Computing. Version 3.1.0. R. Foundation for Statistical Computing, Vienna, Austria.

Reveneau, C., S. K. R. Karnati, E. R. Oelker, and J. L. Firkins. 2012 Interaction of unsaturated fat or coconut oil with monensin in lactating dairy cows fed 12 times daily. I. Protozoal abundance, nutrient digestibility, and microbial protein flow to the omasum. J. Dairy Sci. 95:2046-2060. 
Russell, J. B., R. E. Muck, and P. J. Weimer. 2009. Quantitative analysis of cellulose degradation and growth of cellulolytic bacteria in the rumen. FEMS Microbiol. Ecol. 67:183-197.

Russell, J. B., J. D. O'Connor, D. G. Fox, P. J. Van Soest, and C. J. Sniffen. 1992. A net carbohydrate and protein system for evaluating cattle diets: I. Ruminal fermentation. J. Anim. Sci. 70:35513561.

SAS Institute. 1999. SAS user's guide: Statistics 8.2 ed. SAS Inst. Inc., Cary, NC.

Schmidely, P., F. Glasser, M. Doreau, and D. Sauvant. 2008. Digestion of fatty acids in ruminants: A meta-analysis of flows and variation factors. 1. Total fatty acids. Animal 2:677-690.

St-Pierre, N. R. 2001. Invited review: Integrating quantitative findings from multiple studies using mixed model methodology. J. Dairy Sci. 84:741-755.

St-Pierre, N. R. 2003. Reassessment of biases in predicted nitrogen flows to the duodenum by NRC 2001. J. Dairy Sci. 86:344-350.

Taylor, J. R. 1997. An Introduction to Error Analysis: The Study of Uncertainties in Physical Measurements. University Science Books, Sausalito, CA.

Titgemeyer, E. C. 1997. Design and interpretation of nutrient digestion studies. J. Anim. Sci. 75:2235-2247.
Van Amburgh, M. E., E. A. Collao-Saenz, R. J. Higgs, D. A. Ross, E. B. Recktenwald, E. Raffrenato, L. E. Chase, T. R. Overton, J. K. Mills, and A. Foskolos. 2015. The Cornell Net Carbohydrate and Protein System: Updates to the model and evaluation of version 6.5. J. Dairy Sci. 98:6361-6380.

Vlaeminck, B., V. Fievez, A. R. J. Cabrita, A. J. M. Fonseca, and R. J. Dewhurst. 2006. Factors affecting odd- and branched-chain fatty acids in milk: A review. Anim. Feed Sci. Technol. 131:389-417.

Wang, C., Q. Liu, Y. L. Zhang, C. X. Pei, S. L. Zhang, Y. X. Wang, W. Z. Yang, Y. S. Bai, Z. G. Shi, and X. N. Liu. 2015. Effects of isobutyrate supplementation on ruminal microflora, rumen enzyme activities and methane emissions in Simmental steers. J. Anim. Physiol. Anim. Nutr. (Berl.) 99:123-131.

Weiss, W. P., H. R. Conrad, and N. R. St. Pierre. 1992. A theoretically-based model for predicting total digestible nutrient values of forages and concentrates. Anim. Feed Sci. Technol. 39:95-110.

White, R. R., Y. Roman-Garcia, and J. L. Firkins. 2016. Meta-analysis of postruminal microbial protein flows in dairy cattle. II. Approaches to and implications of more mechanistic prediction. J. Dairy Sci. 99:7932-7944. http://dx.doi.org/10.3168/jds.201510662. 